\title{
Researchers' experiences of optimising complex health interventions before full-scale RCTs: results from an exploratory multiple case study
}

\author{
Sara Levati ${ }^{1 *}$, Suzanne Hagen ${ }^{1}$, Cam Donaldson ${ }^{3}$, Mary Wells $^{2}$ \\ From 3rd International Clinical Trials Methodology Conference \\ Glasgow, UK. 16-17 November 2015
}

\section{Background}

Given the current financial constraints upon health services research and the failure of many trials to establish whether the lack of intervention effect is due to suboptimal intervention design or implementation failure, it is increasingly important to consider pre-trial methods that a) provide leads on how the intervention works, and b) help maximise chances for the intervention to be effective. However, the decision-making processes of, and specific benefits associated with conducting pre-trial optimisation studies are still unclear. This multiple case study was conducted to gain researchers' experiences and views of the process of optimising complex health interventions.

\section{Methods}

This exploratory multiple case study focused on a spectrum of different types of complex interventions. A scoping review conducted in advance informed the design, sampling and methods adopted. A total of 15 cases were explored in-depth, using semi-structured interviews as the main data collection strategy.

\section{Results}

Among the main benefits, optimisation processes allowed researchers to anticipate the potential effects of the intervention and to establish whether to embark on a costly full-scale RCT. However, the usefulness of optimisation may be limited by the assumptions and hypothetical circumstances on which processes are often based. Decisions about which optimisation methods to adopt are influenced by several elements, including the evidence available, the

${ }^{1}$ NMAHP Research Unit - Glasgow Caledonian University, Glasgow, UK Full list of author information is available at the end of the article experience of the research team, the target of the intervention (i.e. single individuals or groups), and the mechanisms of action of the intervention.

\section{Conclusions}

The findings will inform the development of optimisation study guidelines for researchers striving to develop effective complex health interventions.

\section{Authors' details}

'NMAHP Research Unit - Glasgow Caledonian University, Glasgow, UK. ${ }^{2}$ NMAHP Research Unit - University of Stirling, Stirling, UK. ${ }^{3}$ Yunus Centre for Social Business and Health, Glasgow Caledonian University, Glasgow, UK.

Published: 16 November 2015

\section{doi:10.1186/1745-6215-16-S2-O29}

Cite this article as: Levati et al.: Researchers' experiences of optimising complex health interventions before full-scale RCTs: results from an exploratory multiple case study. Trials 2015 16(Suppl 2):O29.

Submit your next manuscript to BioMed Central and take full advantage of:

- Convenient online submission

- Thorough peer review

- No space constraints or color figure charges

- Immediate publication on acceptance

- Inclusion in PubMed, CAS, Scopus and Google Scholar

- Research which is freely available for redistribution 